\title{
New objects can capture attention without a unique luminance transient
}

\author{
Christopher C. Davoli, Jason W. Suszko, and Richard A. Abrams \\ Washington University, St. Louis, Missouri
}

\begin{abstract}
Recent evidence has suggested that new objects capture attention solely because they are typically accompanied by a unique luminance transient. In the present study, we presented a stationary pattern mask after an array of placeholders but before a subsequent search display. This allowed all of the search elements to be presented simultaneously, thereby eliminating the unique luminance transient associated with the appearance of any new objects. Under these circumstances, new objects still captured attention. In another experiment, we jiggled the mask. This caused new objects to lose their advantage. We discuss implications for the importance of new objects, and the attentional consequences of motion.
\end{abstract}

We live in a complex, dynamic visual world, where objects frequently enter and leave our field of view. Because of this, researchers have sought to understand the manner in which our attentional system responds to new objects. A commonly held belief is that new objects capture attention automatically (Enns, Austen, Di Lollo, Rauschenberger, \& Yantis, 2001; Jonides \& Yantis, 1988; Müller \& Rabbitt, 1989; Rauschenberger, 2003; Yantis \& Hillstrom, 1994; Yantis \& Jonides, 1984, 1996). From an evolutionary standpoint, it seems reasonable for new objects to receive attentional priority because they are often critically important - such as when a predator appears unexpectedly.

However, despite considerable interest in the topic, there is still some debate concerning the underlying explanation for attentional capture by new objects. On the one hand, it has been suggested that new objects capture attention because each object in a scene must be "registered" in some internal representation. According to this new-object hypothesis, an "object file" (Kahneman, Treisman, \& Gibbs, 1992) must be created for each new object, and it is the process of creating the object file that draws attention (Yantis \& Hillstrom, 1994; Yantis \& Jonides, 1996). Evidence consistent with this explanation comes from a number of sources (e.g., Enns et al., 2001; Jonides \& Yantis, 1988; Müller \& Rabbitt, 1989; Rauschenberger, 2003; Yantis \& Hillstrom, 1994; Yantis \& Jonides, 1984, 1996).

According to an alternative explanation, however, new objects capture attention because they are typically accompanied by a unique luminance transient. This explanation is plausible because, in most studies of attentional capture, the objects to be searched were defined on the basis of luminance differences with the background (e.g., Yantis \& Jonides, 1984; but see Rauschenberger \& Yantis, 2001). Indeed, attention can even be drawn to old objects by suf- ficiently large luminance changes (Rauschenberger, 2003) or concurrent changes in contrast polarity and contrast (Enns et al., 2001, Experiment 5). If new objects attract attention due solely to luminance changes, then considerable doubt would be cast on the new-object hypothesis.

In order to examine the importance of luminance changes for capture by new objects, some researchers have utilized objects that were defined by discontinuities other than luminance (e.g., Yantis \& Hillstrom, 1994), and under such circumstances the new objects continued to capture attention. However, it is possible that local luminance changes were responsible for the advantage observed there (Gellatly, Cole, \& Blurton, 1999; Theeuwes, 1995). As a result, it remains unclear whether the attentional advantage enjoyed by new objects can be attributed to factors other than low-level luminance changes (but see Rauschenberger \& Yantis, 2001).

Recently, Franconeri, Hollingworth, and Simons (2005) devised a novel method for presenting a new object without a unique transient: They briefly occluded all of the objects in the display at the moment when the new object was introduced. When the occluder was removed, all of the objects experienced a transient, and importantly, there was no unique transient associated with any new objects. This method provided an opportunity to conduct a more definitive test of the new-object hypothesis than what had been possible so far. And the results of such a test were clear: The new objects, without a unique luminance transient, were unable to capture attention (Franconeri et al., 2005).

Nevertheless, some details of the method used by Franconeri et al. (2005) may have prevented them from finding a new-object advantage. In particular, in their study, an annular shape initially surrounded an array of placeholders. The annulus then shrank until it occluded the placeholders, at which time the placeholders changed to letters and one

R.A.Abrams, rabrams@wustl.edu 
additional letter was added to the (occluded) display. The annulus continued shrinking to reveal the search elements. Of concern is the possibility that the shrinking motion of the occluder itself was distracting - perhaps attracting attention to itself. As a result, it might have been difficult to observe any advantage of a new versus an old object. Indeed, several researchers have recently shown attentional effects of various kinds of motion suggesting the possibility that the motion may have played a key role (e.g., Abrams \& Christ, 2003; Franconeri \& Simons, 2003). However, the general method devised by Franconeri et al. (2005) does not require a moving occluder in order to test questions about the role of transients in attentional capture by new objects. We performed such a test in Experiment 1.

\section{EXPERIMENTS 1A AND 1B}

In Experiment 1, we used Franconeri et al.'s (2005) technique for presenting a new object without a unique transient, but without the potential disadvantage introduced by a moving occluder. In the experiment, subjects saw an array of placeholders, followed by a pattern mask (during which time the old objects were not visible). The mask was removed and replaced by a search display that contained letters in locations previously occupied by placeholders, plus one letter in a new location. In separate experiments, we studied two different mask durations: $100 \mathrm{msec}(\mathrm{Ex}-$ periment 1A) and $400 \mathrm{msec}$ (Experiment 1B). ${ }^{1}$

\section{Method}

Subjects. Thirteen naive Washington University undergraduates participated in Experiment 1A, and 15 participated in Experiment 1B. Each experimental session lasted $50 \mathrm{~min}$. The subjects received course credit for their participation.

Apparatus and Procedure. The subjects were seated in front of a computer screen in a dimly lit room. Stimuli were presented on an 18 -in. monitor operating at a rate of $72 \mathrm{~Hz}$, with a resolution of $640 \times 480$ pixels.

Figure 1 shows the sequence of events that occurred on each trial. Each trial began with a black central fixation cross $\left(0.8^{\circ} \times\right.$ $0.8^{\circ}$ ) against a white background. After $500 \mathrm{msec}$, either three or seven placeholders appeared in the display. Placeholders were black, block figure eights measuring $1.6^{\circ} \times 0.8^{\circ}$. The location of each placeholder was randomly chosen, with the following restrictions:
Placeholders could not occur within $0.4^{\circ}$ of each other; placeholders could not occur inside the imaginary $0.8^{\circ} \times 0.8^{\circ}$ area demarcated by the fixation cross; and placeholders could not occur within $4.0^{\circ}$ of the edges of the screen. After $1,000 \mathrm{msec}$, the screen was cleared and a pattern mask was presented. The pattern mask was created by successively connecting 100 randomly selected points with line segments. The mask appeared for $100 \mathrm{msec}$ in Experiment 1A, or $400 \mathrm{msec}$ in Experiment 1B, after which the screen was cleared and the search display was presented. The search display consisted of the fixation cross, old objects, and a new object. Old objects were created by removing segments of placeholders to form letters, and always occurred in the same locations as the placeholders they were modified from. The location of the new object was randomly chosen, with the same restrictions as described for the placeholders. There was always one target letter per search display (either $\mathrm{H}$ or $\mathrm{S}$ ). Each of the remaining letters in the search display was a distractor, and each distractor was randomly chosen to be either E or U. Every potential letter in the search display $(\mathrm{E}, \mathrm{H}, \mathrm{S}, \mathrm{U})$ could be made by removing two segments from a placeholder. The subjects were instructed to discriminate which target letter was present in the search display and to respond as quickly and as accurately as possible by pressing a key ("z" or " ")") on the keyboard. One key was assigned to each target letter. Response latency was timed from the onset of the search display. The subjects were given on-screen error feedback if they responded in less than $100 \mathrm{msec}$ ("Too fast!"), did not respond within 1,500 msec ("Too slow!"), or responded with any key other than the correct one ("Wrong key pressed!"). Trials terminated after a correct response or after error feedback. There was a 2-sec delay between trials, in which only the white background was visible.

Design. After 10 practice trials, the subjects completed seven blocks of 64 trials each, for a total of 448 experimental trials. The experiment was a 2 (number of distractors: 3 or 7 ) $\times 2$ (target condition: new or old) $\times 2$ (target identity: $\mathrm{H}$ or $\mathrm{S}$ ) within-subjects design. In the three-distractor condition, the target was the new object on one quarter of the trials; in the seven-distractor condition, the target was the new object on one eighth of the trials. Thirty-two trials were required to produce a complete set with the designated target probabilities. Each block contained two such sets, with trials within each block randomly ordered. The subjects were provided with a break at the end of each block. Mapping of target letter to response key was counterbalanced across subjects.

\section{Results}

Experiment 1A. Errors occurred on $4.7 \%$ of trials. One subject was excluded from the analysis due to excessive errors $(18.5 \%)$.

Figure 2 shows the mean reaction time (RT) as a function of target condition and number of distractors.

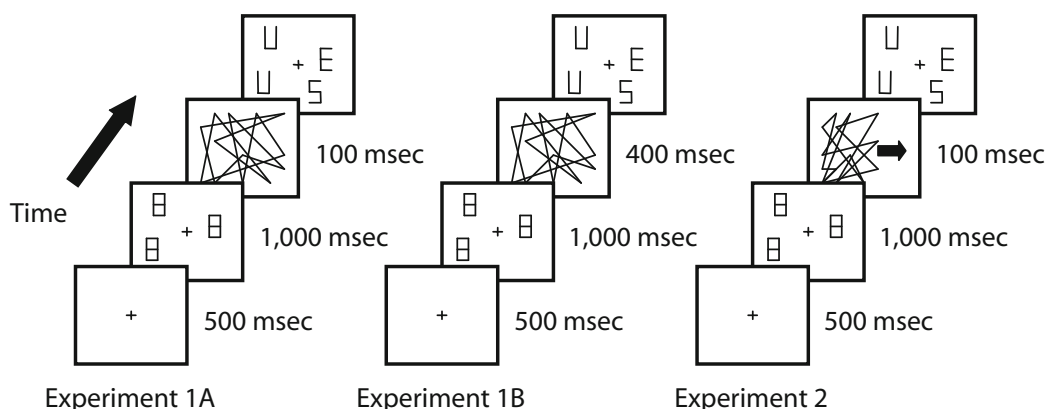

Figure 1. Trial events for Experiments 1A, 1B, and 2. The mask in the third frame of each experiment is not an exact reproduction (see text for a detailed explanation). The arrow in the third frame of Experiment 2 designates motion of the mask, and was not visible in the display. Figure not to scale. 
A 2 (number of distractors) $\times 2$ (target condition) repeated measures ANOVA was conducted on the RTs. The analysis revealed that the subjects were faster overall when there were three distractors than when there were seven $[F(1,11)=22.2, p<.001]$, and when the target was new than when it was old $[F(1,11)=18.6, p<.005]$. As seen in the figure, we also observed an interaction between number of distractors and target condition $[F(1,11)=$ $9.9, p<.01]$. Search slopes were computed to determine how RTs varied as a function of the number of distractors: When the target was an old object, the search slope was $13.6 \mathrm{msec} /$ item. When the target was a new object, the search slope was $6.9 \mathrm{msec} /$ item.

Mean error percentages are shown in Table 1 . A $2 \times 2$ ANOVA revealed a significantly greater percentage of errors in the seven-distractor condition than in the threedistractor condition $[F(1,11)=5.4, p<.05]$. There was a significantly greater percentage of errors when the target was old than when the target was new $[F(1,11)=49.9$, $p<.0001]$. There was a significant interaction in error percentages between number of distractors and target condition $[F(1,11)=9.5, p<.05]$. These error patterns are in directions that do not indicate a speed-accuracy trade-off.

Experiment 1B. Figure 3 shows mean RT as a function of target condition and number of distractors. A 2 (number of distractors) $\times 2$ (target condition) repeated measures ANOVA was conducted on RT. The analysis revealed that the subjects were faster overall when there were three distractors than when there were seven $[F(1,14)=19.1$, $p<.001]$, and when the target was new than when it was old $[F(1,14)=18.6, p<.001]$. As seen in the figure, we also observed an interaction between number of distractors and target condition $[F(1,14)=5.4, p<.05]$. When the target was an old object, the search slope was $11.0 \mathrm{msec} /$ item. When the target was a new object, the search slope was $5.5 \mathrm{msec} /$ item.

Errors occurred on $7.0 \%$ of trials. Mean error percentages are shown in Table 1 . A $2 \times 2$ ANOVA revealed a significantly greater percentage of errors in the sevendistractor condition than in the three-distractor condition $[F(1,14)=18.1, p<.001]$. There was a significantly greater percentage of errors when the target was old than when it was new $[F(1,14)=49.3, p<.0001]$. There was a significant interaction in error percentages between number of distractors and target condition $[F(1,14)=25.1$, $p<.0005]$. These error patterns are in directions that do not indicate a speed-accuracy trade-off.

Between-subjects analysis of Experiments 1A and 1B. An overall ANOVA on RT across Experiments 1A

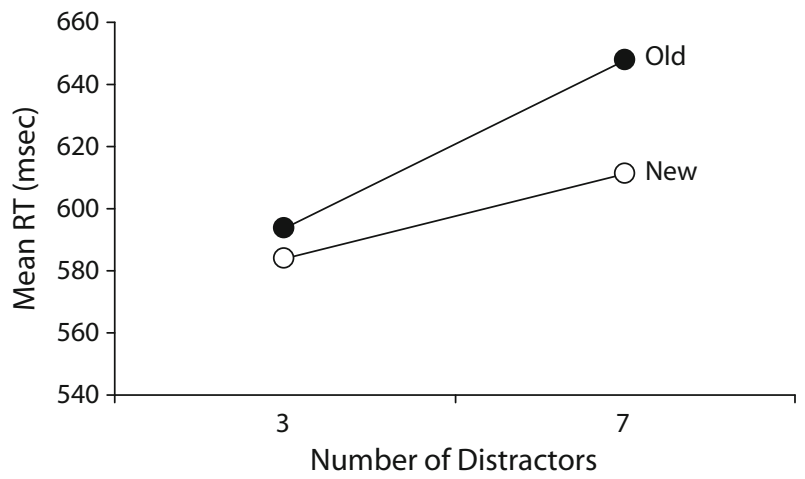

Figure 2. Mean reaction time as a function of target condition and number of distractors for Experiment $1 \mathrm{~A}$.

and $1 \mathrm{~B}$ revealed that the subjects were faster overall when there were three distractors than when there were seven $[F(1,25)=41.6, p<.0001]$, and when the target was new than when it was old $[F(1,25)=36.9, p<.0001]$. There was no main effect of experiment $[F(1,25)<1]$. There was a significant interaction between number of distractors and target condition, indicating a shallower search slope when the target was a new object $[F(1,25)=14.0, p<.005]$. The two-way interactions between number of distractors and experiment, and target condition and experiment, did not reach significance $\left[\right.$ all $\left.F_{\mathrm{S}}(1,25)<1\right]$. The three-way interaction between number of distractors, target condition, and experiment was not significant $[F(1,25)<1]$, suggesting an equivalent new-object benefit in both experiments.

\section{Discussion}

In the present experiment, the subjects found the target letter more quickly when it was a new as opposed to an old object, and search times for new objects were less affected by increases in display size. Those results are consistent with a number of past results showing attentional capture by new objects (e.g., Enns et al., 2001; Jonides \& Yantis, 1988; Müller \& Rabbitt, 1989; Rauschenberger, 2003; Yantis \& Hillstrom, 1994; Yantis \& Jonides, 1984, 1996). Nevertheless, our results were obtained under conditions in which there was not a unique luminance transient associated with the new object. That finding contrasts with those of Franconeri et al. (2005), who found that elimination of unique transients associated with the new objects also eliminated the new-object benefit. ${ }^{2}$

What could explain the discrepancy between our results and those of Franconeri et al. (2005)? One key difference

Table 1

Means $(M)$ and Standard Errors $(S E)$ of Error Percentages for Each Experiment

\begin{tabular}{|c|c|c|c|c|c|c|c|c|c|c|c|c|}
\hline \multirow[b]{3}{*}{ Target } & \multicolumn{4}{|c|}{ Experiment 1A } & \multicolumn{4}{|c|}{$\begin{array}{l}\text { Experiment 1B } \\
\text { umber of Distractors }\end{array}$} & \multicolumn{4}{|c|}{ Experiment 2} \\
\hline & \multicolumn{2}{|c|}{3} & \multicolumn{2}{|c|}{7} & \multicolumn{2}{|c|}{3} & \multicolumn{2}{|c|}{7} & \multicolumn{2}{|c|}{3} & \multicolumn{2}{|c|}{7} \\
\hline & $M$ & $S E$ & $M$ & $S E$ & $M$ & $S E$ & $M$ & $S E$ & $M$ & $S E$ & $M$ & $S E$ \\
\hline New & 0.3 & 0.06 & 0.1 & 0.02 & 0.4 & 0.07 & 0.1 & 0.03 & 0.3 & 0.08 & 0.1 & 0.01 \\
\hline Old & 2.7 & 0.43 & 4.5 & 0.74 & 3.9 & 0.58 & 6.8 & 1.00 & 3.3 & 0.71 & 4.2 & 1.00 \\
\hline
\end{tabular}




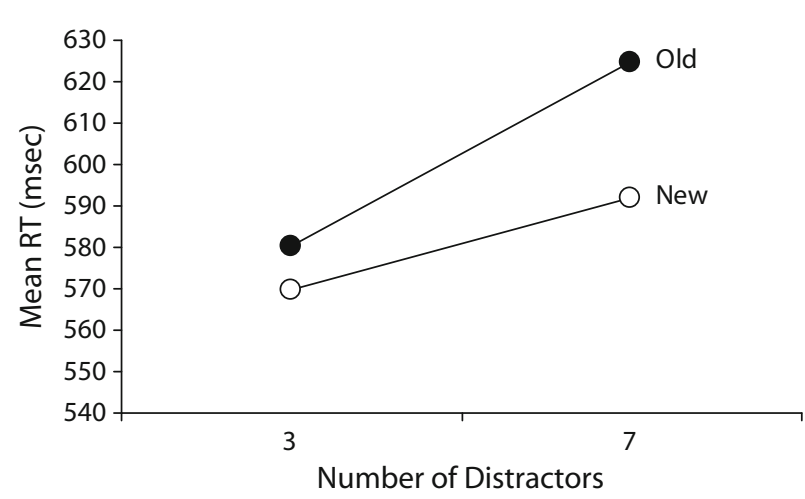

Figure 3. Mean reaction time as a function of target condition and number of distractors for Experiment 1B.

between our method and that of Franconeri et al. involved the nature of the occluder. In particular, in the Franconeri et al. study, the occluder moved over the search elements in the display. However, in the present experiment, we used a stationary pattern mask as an occluder. Both stationary masks and moving shapes can in theory serve as effective occluders. But it is possible that the motion of the occluder in the Franconeri et al. study may have done more than to simply eliminate the unique transient associated with the new object in the display. One possible effect of the motion might be to attract attention to the occluder itself, somehow impairing search. Several recent reports have shown that certain types of motion do indeed capture attention, consistent with this possibility (Abrams \& Christ, 2003; Franconeri \& Simons, 2003). It is also possible that the motion of the occluder in the Franconeri et al. (2005) study had some other effect that might have disrupted the representation of old objects - causing all of the search elements to be interpreted as new. As a result, objects that were truly new enjoyed no advantage over the old ones. Importantly, if this explanation is correct, then Franconeri et al.'s failure to find a new-object advantage might be due to the specific nature of their occluder, and not due to the elimination of unique luminance transients, as they suggested. Experiment 2 tested the hypothesis that the motion of the occluder was responsible for elimination of the new-object advantage.

\section{EXPERIMENT 2}

Experiment 2 was identical to Experiment 1A, but here, a moving pattern mask was used as an occluder, as opposed to a stationary one. If motion of the mask in the Franconeri et al. (2005) study, and not the occlusion caused by it, was responsible for the elimination of the new-object benefit, then that benefit should also be eliminated here.

\section{Method}

Subjects. Twelve naive Washington University undergraduates participated in one 50-min session each, for course credit.

Apparatus, Procedure, and Design. Experiment 2 was identical to Experiment 1A, with the following exception. The pattern mask was created in the same manner as in Experiment 1, with the additional restriction that no point could fall within $1.6^{\circ}$ of the right edge of the screen. The mask was presented initially for $50 \mathrm{msec}$. The entire mask then shifted to the right, leaving a $1.6^{\circ}$ blank strip along the left edge of the screen. This was presented for $50 \mathrm{msec}$. The screen was then cleared and the search display was presented. Due to the constraints on the placement of the search letters noted earlier, letters did not appear in the $1.6^{\circ}$ strips at the right and left edges of the display.

\section{Results}

Figure 4 shows mean RT as a function of target condition and number of distractors. A 2 (number of distractors) $\times 2$ (target condition) ANOVA was conducted on RT. The analysis revealed that the subjects were faster overall when there were three distractors than when there were seven $[F(1,11)=30.3, p<.0005]$. No other main effects or interactions reached significance [all $F_{\mathrm{s}}(1,11)<1$, n.s.]. Most importantly, there was no interaction between number of distractors and target condition, indicating no new-object effect, as can be seen in Figure 3. When the target was an old object, the search slope was $11.5 \mathrm{msec} /$ item. When the target was a new object, the search slope was $11.0 \mathrm{msec} /$ item.

Errors occurred on $4.8 \%$ of trials. Mean error percentages are shown in Table 1. A $2 \times 2$ ANOVA revealed a significantly greater percentage of errors when the target was old than when it was new $[F(1,11)=20.3, p<$ $.001]$. This difference between old- and new-target trials suggests that subjects might retain information, at some level, about the target condition. However, importantly (and interestingly), that information did not permit the new objects to capture attention: The interaction between number of distractors and target condition, which could potentially affect the search slopes, was not significant $[F(1,11)<1]$.

Combined analysis of Experiments $1 \mathrm{~A}$ and 2. We also conducted an analysis of the combined results of Experiments $1 \mathrm{~A}$ and 2 (these two experiments are the most closely comparable). The analysis revealed that the subjects were faster when there were three distractors than when there were seven $[F(1,22)=51.9, p<.0001]$, and when the target was new than when it was old $[F(1,22)=$ $5.5, p<.05]$. There was a significant interaction between experiment and target condition $[F(1,22)=9.7, p<.01]$,

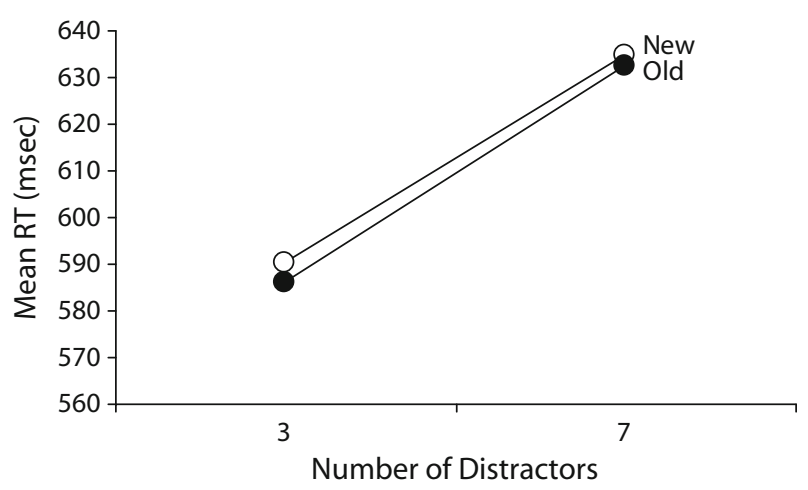

Figure 4. Mean reaction time as a function of target condition and number of distractors for Experiment 2. 
indicating that subjects were faster when the target was a new object $(M=597.5, S E=19.0)$ than when it was an old object $(M=620.7, S E=17.6)$ in Experiment $1 \mathrm{~A}$, but that there was no difference between new $(M=612.6$, $S E=19.0)$ and old $(M=609.4, S E=17.6)$ objects in Experiment 2. There was a significant interaction between number of distractors and target condition overall $[F(1,22)=5.5, p<.05]$. When the target was an old object, the search slope was $12.6 \mathrm{msec} / \mathrm{item}$; when the target was a new object, the search slope was $9.0 \mathrm{msec} / \mathrm{item}$. Most importantly, there was a marginally significant number of distractors $\times$ target condition $\times$ experiment interaction on $\mathrm{RT}[F(1,22)=4.152, p=.054]$. This interaction indicates that the number of distractors $\times$ target condition interaction in Experiment $1 \mathrm{~A}$ indicated capture by new objects there, but the lack of an interaction in Experiment 2 reveals the absence of attentional capture. No other interactions reached significance [all $F_{\mathrm{S}}(1,22)<1$, n.s.].

\section{Discussion}

In the present experiment, a moving mask was used to occlude the search display when a new object was added. The new-object advantage found in Experiment 1 was subsequently eliminated. By extension, this suggests that the motion of the mask, and not the occlusion it provided, is responsible for eliminating the new-object benefit here and in the experiment of Franconeri et al. (2005). ${ }^{3}$

\section{GENERAL DISCUSSION}

New objects typically appear with a unique luminance transient, making it unclear whether attentional capture by new objects is mediated by a need to represent a new element in the visuospatial world, or by a sensitivity to local changes in luminance. Franconeri et al. (2005) devised a novel method for presenting new objects without a unique luminance transient: Immediately before introduction of the new object, all of the objects in the display were briefly occluded. They found that new objects, without unique transients, failed to capture attention. However, Franconeri et al. used an occluder that moved over the search elements in the display. Several reports have shown that certain types of motion capture attention (e.g., Abrams \& Christ, 2003; Franconeri \& Simons, 2003). Thus, it is possible that the motion of the occluder may have attracted attention to the occluder itself, and influenced the search. In Experiment 1, we used a stationary pattern mask to eliminate the unique luminance transient associated with the new object, and found a new-object benefit. In Experiment 2, a similar, but moving mask eliminated the new-object benefit, supporting the claim that motion of the occluder, and not the elimination of the unique luminance transient, was responsible for eliminating the new-object benefit here and in the Franconeri et al. (2005) study.

If motion of an occluder eliminates the new-object benefit, one may ask why the motion of Franconeri et al.'s (2005) annulus did not eliminate the new-object benefit in their control experiment. We propose that one way in which a moving occluder might affect search is for the distraction caused by the motion to disrupt some memory for the old, occluded objects. In the control experiment of Franconeri et al., the annulus passed behind the array of objects, instead of over them. In this instance, the old objects remained entirely visible throughout the trial, and there was no need for the subjects to retain them in memory. As a result, the motion of the annulus was not disruptive. Furthermore, in the control condition, the new objects appeared with a unique luminance transient, which gave them a distinct attentional advantage over the other items in the display.

Some of our results may be informative regarding questions about object permanence. In Experiment 1B, we found that new objects enjoyed an advantage over old objects even after $400 \mathrm{msec}$ of old-object absence. This implies that old-object representations were held in memory for $400 \mathrm{msec}$, which is considerably longer than estimates made by earlier researchers. For example, Yantis and Gibson (1994) estimated that objects can be retained in memory for a duration of $100 \mathrm{msec}$. However, they induced the appearance of a new object by removing one object from an array and then re-presenting it after $100 \mathrm{msec}$. Also, in the Yantis and Gibson study, the disappearance and reappearance of one object created a local luminance transient each time. In our study, every object disappeared and reappeared simultaneously, so all of the objects experienced a transient. It is possible that these methodological differences are responsible for the differences in the estimates of object continuity.

In the present study, new objects have withstood another test of their importance, this time in a method that strips them of any low-level luminance advantage. Perhaps modifications of the method used here can provide further insights into scene perception and stimulus-driven attention.

\section{AUTHOR NOTE}

The authors thank Robert Rauschenberger, Angus Gellatly, and an anonymous reviewer for their helpful comments on an earlier version of the article. Correspondence concerning this article should be addressed to R. A. Abrams, Department of Psychology, Washington University, St. Louis, MO 63130 (e-mail: rabrams@wustl.edu).

\section{REFERENCES}

Abrams, R. A., \& Christ, S. E. (2003). Motion onset captures attention. Psychological Science, 14, 427-432.

Enns, J. T., Austen, E. L., Di Lollo, V., Rauschenberger, R., \& YANTIS, S. (2001). New objects dominate luminance transients in setting attentional priority. Journal of Experimental Psychology: Human Perception \& Performance, 27, 1287-1302.

Franconeri, S. L., Hollingworth, A., \& Simons, D. J. (2005). Do new objects capture attention? Psychological Science, 16, 275-281.

Franconeri, S. L., \& Simons, D. J. (2003). Moving and looming stimuli capture attention. Perception \& Psychophysics, 65, 999-1010.

Gellatly, A., Cole, G., \& Blurton, A. (1999). Do equiluminant object onsets capture visual attention? Journal of Experimental Psychology: Human Perception \& Performance, 25, 1609-1624.

Jonides, J., \& Yantis, S. (1988). Uniqueness of abrupt visual onset in capturing attention. Perception \& Psychophysics, 43, 346-354.

Kahneman, D., Treisman, A., \& Gibbs, B. J. (1992). The reviewing of object files: Object-specific integration of information. Cognitive Psychology, 24, 174-219. 
Müller, H. J., \& Rabbitt, P. M. A. (1989). Reflexive and voluntary orienting of visual attention: Time course of activation and resistance to interruption. Journal of Experimental Psychology: Human Perception \& Performance, 15, 315-330.

RAUSCHENBERGER, R. (2003). When something old becomes something new: Spatiotemporal object continuity and attentional capture. Journal of Experimental Psychology: Human Perception \& Performance, 29, 600-615.

RAuschenberger, R., \& YANTIS, S. (2001). Attentional capture by globally defined objects. Perception \& Psychophysics, 63, 1250-1261.

TheEUwes, J. (1995). Abrupt luminance change pops out; abrupt color change does not. Perception \& Psychophysics, 57, 637-644.

YANTIS, S., \& GiBson, B. S. (1994). Object continuity in apparent motion and attention. Canadian Journal of Experimental Psychology, 48, 182-204.

Yantis, S., \& Hillstrom, A. P. (1994). Stimulus-driven attentional capture: Evidence from equiluminant visual objects. Journal of Experimental Psychology: Human Perception \& Performance, 20, 95-107.

YAntis, S., \& Jonides, J. (1984). Abrupt visual onsets and selective attention: Evidence from visual search. Journal of Experimental Psychology: Human Perception \& Performance, 10, 601-621.

YANTIS, S., \& JonIDES, J. (1996). Attentional capture by abrupt onsets: New perceptual objects or visual masking? Journal of Experimental Psychology: Human Perception \& Performance, 22, 1505-1513.

\section{NOTES}

1. We conducted Experiment 1B to be sure that the results of Experiment $1 \mathrm{~A}$ could not be explained by sensory holdover of old-object locations, due to too short a mask duration.
2. We also conducted an additional experiment that was similar to Experiments $1 \mathrm{~A}$ and $1 \mathrm{~B}$. In that experiment, we presented a 50-msec blank interval between the placeholder display and the search display, instead of a pattern mask. We found a significant interaction between number of distractors and target condition, indicating a new-object benefit $[F(1,10)=5.07, p<.05]$. When the target was an old object, the search slope was $8.2 \mathrm{msec} /$ item; when the target was a new object, the search slope was $4.2 \mathrm{msec} /$ item. Although adding a blank interval between the placeholder display and the search display should in itself be a sufficient means for presenting a new object without a unique transient, our particular blank interval was rather short in duration, and may have allowed for retention of old-object locations on a sensory level. Therefore, we chose to add a pattern mask and increase the duration of the interstimulus interval in Experiments 1A and 1B.

3. It is worth noting that motion rendered in digital computer displays involves multiple onsets and offsets as the moving objects are drawn, erased, and then redrawn in a new location. This property was present in the moving mask in Experiment 2, as well as for the moving annulus used by Franconeri et al. (2005). Thus, in order to be certain that motion was the key feature of the occlusion that was responsible for elimination of the new-object effect, it would be necessary to conduct additional experiments in which the multiple onsets and offsets were equated over displays with both moving and nonmoving occluders. Such experiments could help to further elucidate the underlying mechanisms. We thank Angus Gellatly for bringing this to our attention.

(Manuscript received January 31, 2006; revision accepted for publication June 1, 2006.) 